\title{
Saccharomyces cerevisiae as a Toolkit for COP9 Signalosome Research
}

\author{
Dana Harshuk-Shabso ${ }^{1,+}$, Noam Castel ${ }^{2,+}$, Ran Israeli ${ }^{3}$, Sheri Harari ${ }^{3}$ and Elah Pick $1,2,3, *$ (D) \\ 1 Department of Human Biology, Faculty of Natural Sciences, University of Haifa, Haifa 31905, Israel; \\ harshukdana@gmail.com \\ 2 Department of Evolutionary and Environmental Biology, Faculty of Natural Sciences, University of Haifa, \\ Haifa 31905, Israel; noamcastel@gmail.com \\ 3 Department of Biology and Environment, Faculty of Natural Sciences, University of Haifa at Oranim, \\ Tivon 36006, Israel; ranisraeli1988@gmail.com (R.I.); sherryperets@gmail.com (S.H.) \\ * Correspondence: elahpic@research.haifa.ac.il \\ $\dagger$ Shared co-first authorship.
}

Citation: Harshuk-Shabso, D.; Castel, N.; Israeli, R.; Harari, S.; Pick, E. Saccharomyces cerevisiae as a Toolkit for COP9 Signalosome Research. Biomolecules 2021, 11, 497. https:// doi.org/10.3390/biom11040497

Academic Editor: Maria E. Gaczyńska

Received: 11 January 2021

Accepted: 20 March 2021

Published: 25 March 2021

Publisher's Note: MDPI stays neutral with regard to jurisdictional claims in published maps and institutional affiliations.

Copyright: (c) 2021 by the authors. Licensee MDPI, Basel, Switzerland. This article is an open access article distributed under the terms and conditions of the Creative Commons Attribution (CC BY) license (https:// creativecommons.org/licenses/by/ $4.0 /)$.

\begin{abstract}
The COP9 signalosome (CSN) is a highly conserved eukaryotic multi-subunit enzyme, regulating cullin RING ligase activities and accordingly, substrate ubiquitination and degradation. We showed that the CSN complex of Saccharomyces cerevisiae that is deviated in subunit composition and in sequence homology harbors a highly conserved cullin deneddylase enzymatic core complex. We took advantage of the non-essentiality of the S. cerevisiae CSN-NEDD8/Rub1 axis, together with the enzyme-substrate cross-species activity, to develop a sensitive fluorescence readout assay, suitable for biochemical assessment of cullin deneddylation by CSNs from various origins. We also demonstrated that the yeast catalytic subunit, CSN5/Jab1, is targeted by an inhibitor that was selected for the human orthologue. Treatment of yeast by the inhibitor led to the accumulation of neddylated cullins and the formation of reactive oxygen species. Overall, our data revealed S. cerevisiae as a general platform that can be used for studies of CSN deneddylation and for testing the efficacy of selected CSN inhibitors.
\end{abstract}

Keywords: COP9 signalosome; NEDD8; Rub1; CSN5/Jab1; CSN5i-3; cullin RING E3 ligase

\section{Introduction}

Cells, tissues, and organismal health depend on a complex network of homeostasis between protein synthesis, functioning, and degradation, which are collectively referred to as "proteostasis". When proteostasis breaks down, diseases such as cancer, inflammation, or neurodegeneration can appear [1]. Indeed, various components of proteostasis are attractive targets for therapeutic intervention [2]. Maintenance of proteostasis requires timely degradation of proteins, which are damaged by incorrect translation, and improper folding during synthesis, genetic mutations, or are no longer required due to changes in environmental ques or cellular needs [3]. Two major proteolytic machineries, the ubiquitin proteasome system (UPS) and the lysosomal autophagy, are essential for maintaining cell health [4-6].

Rates of degradation by the UPS have generally been determined by the modification of substrates by ubiquitin $(\mathrm{Ub})[7,8]$. The ubiquitination of UPS substrates requires an enzymatic cascade, starting by E1 (Ub-activating enzyme), which forms a thioester with $\mathrm{Ub}$ following ATP consumption. Next, an E2 (Ub-conjugating enzyme) takes over $\mathrm{Ub}$ from the E1, forming again thioester and transferring the $\mathrm{Ub}$ to a specific substrate, selected by E3 (Ub ligase), which can further form a poly-Ub chain [9-11]. Substrates conjugated primarily with Lys48-linked poly-Ub chains are transferred to the $26 \mathrm{~S}$ proteasome complex for degradation $[6,12,13]$. The $26 \mathrm{~S}$ proteasome is symmetric and composed of two subcomplexes: The $20 \mathrm{~S}$ catalytic core particle is located in the center and two $19 \mathrm{~S}$ regulatory 
particles surrounding the $20 \mathrm{~S}$ on both sides. The distal part of the $19 \mathrm{~S}$ particle is referred to as the 19S lid subcomplex [14]. The 19S lid is composed of eight endemic non-ATPase subunits (Rpn3, Rpn5-9, and Rpn11-12) and DSS1/Sem1, which is found in additional complexes [14,15]. Interestingly, the 195 lid is a close homologue of two other complexes: The COP9 signalosome (CSN) and the eukaryotic translation initiation factor 3 (eIF3), which together have been termed as proteasome lid, CSN, and eIF3 (PCI) complexes [14-16]. PCI complexes contain a pair of Mpr-1-PAD1-N-terminal (MPN) domain-containing subunits, sometimes bearing an $\mathrm{MPN}^{+}$metal-binding motif, also known as JAB1-MPN-MOV34 (JAMM) $[17,18]$. The biochemical role ascribed to the $19 \mathrm{~S}$ lid is deubiquitination activity of the $\mathrm{MPN}^{+} / \mathrm{JAMM}$ metalloenzyme, Rpn11 $[19,20]$. Similarly, the CSN complex also harbors metalloprotease activity ascribed to CSN5/Jab (aka Csn5 in Saccharomyces cerevisiae), a direct paralogue of Rpn11 [21]. The great similarity between CSN5 and Rpn11 leads to the fact that their substrates are also paralogous-various Ub-linked proteasome targets for Rpn11; and NEDD8 (aka Rub1 in Saccharomyces cerevisiae) conjugated proteins, namely cullins, for Csn5 [22]. Each cullin serves as a platform for building a modular array of multi-subunit E3 enzymes, known as cullin-RING ligases (CRLs). CRLs are required for the ubiquitination of a wide variety of $26 \mathrm{~S}$ proteasome targets, and the neddylation of cullins activates all of them (Figure 1A) [23,24].
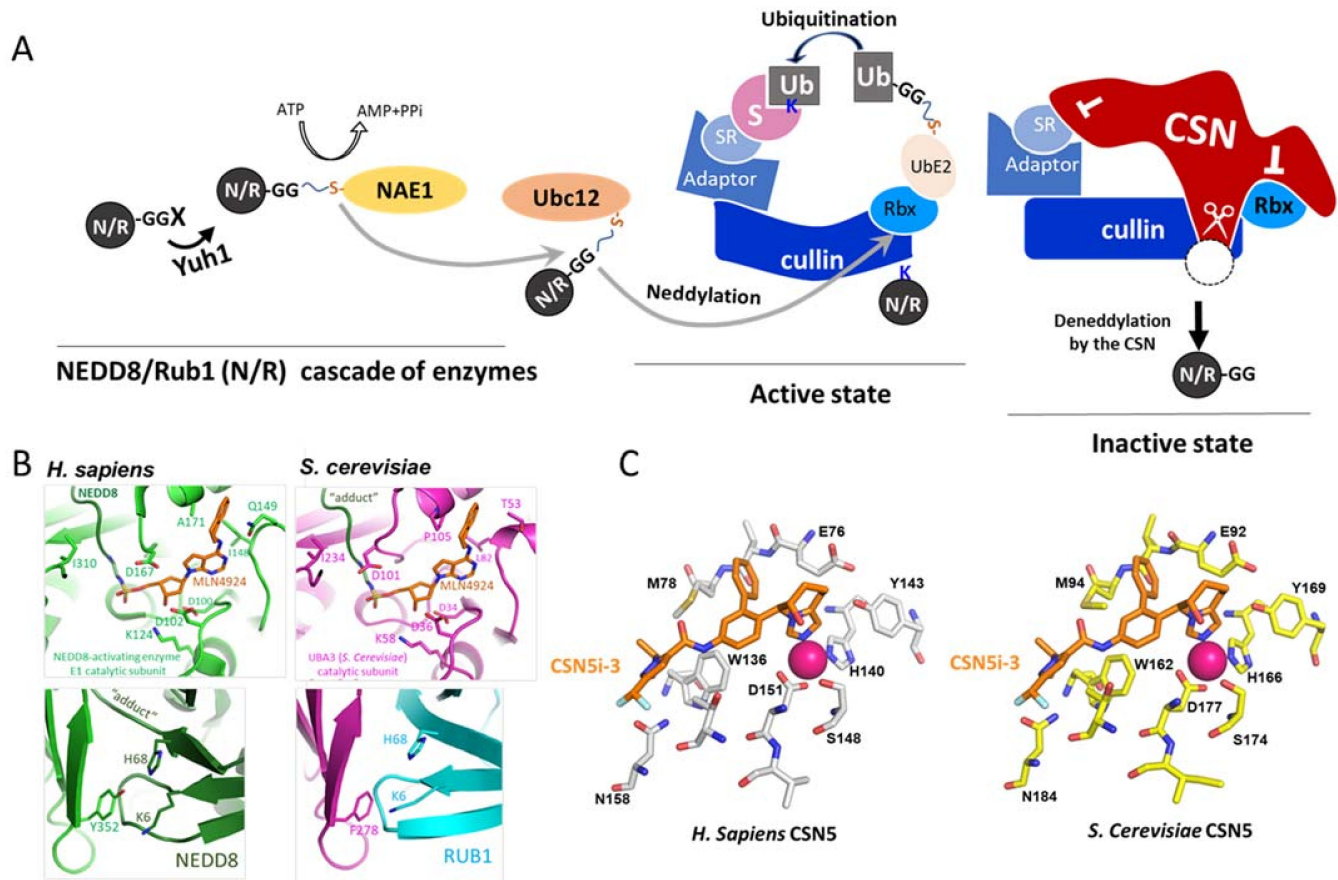

C
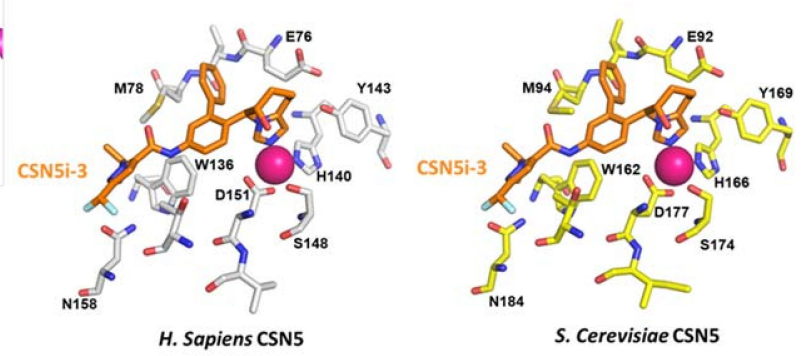

Figure 1. The evolutionarily conserved cullin neddylation/deneddylation enzymes. (A) A schematic model for cullin-RING ligase (CRL) activation and inhibition. NEDD8/Rub1 (N/R) is translated as a precursor that initially needs to be trimmed by the cysteine protease Yuh1 to expose the diglycine motif. Next, N/R is activated by ATP and forms thioester with an E1 (NAE1) enzyme. Following this step, N/R is trans-thiolized to an E2 (Ubc12) enzyme, which interacts with the RING subunit $(\mathrm{Rbx})$ to transfer the $\mathrm{N} / \mathrm{R}$ to a specific lysine $(\mathrm{K})$ residue on a cullin. The N/R modification of cullins activate CRLs, which in return transfer ubiquitin (Ub) from $\mathrm{Ub}$ E2 (UbE2) enzyme to a substrate (S). Subsequently, CRLs are inhibited through N/R hydrolysis by the COP9 signalosome (CSN) complex, resulting in free N/R-GG. Notably, the CSN inhibits CRLs also non-enzymatically, through steric clashes $(\perp$ ). (B) Molecular model of the human (left, green) and Saccharomyces cerevisiae (right, magenta) NAE nucleotide binding sites with MLN4924 (top) or NEDD8/Rub1 (bottom). The S. Cerevisiae homology model was generated using SWISS-MODEL based on the structure of NAE1 in complex with NEDD8 and MLN4924 (PDB ID 3GZN), oriented as previously shown [25]. (C) Predicted active site of the S. cerevisiae Csn5 subunit, bound to the CSN5i-3 inhibitor. Active site of the human crystal structure of CSN5 in complex with the inhibitor CSN5i-3. Homology model was generated using SWISS-MODEL, using the PDB accession code 5JOG as a template, oriented as previously described [26]. Amino acids of the predicted active sites are shown in sticks and the zinc cations are shown in purple spheres. 
The CSN is a highly conserved complex that was first purified from plants as a repressor of light-dependent growth patterns during darkness [27,28]; and from mammalian tissues as a signaling regulator [29]. CSN complexes are essential for the vitality of multicellular organisms, and their loss-of-function mutants display critical pleiotropic phenotypes [30-32]. CSN essentiality has been demonstrated in Arabidopsis thaliana, where loss of any of the subunits proved lethal in the development of seedlings. Similarly, in mice, knockdown of CSN subunits is fatal in the early embryonic stage [33]. Although critical in multicellular organisms, the loss of CSN subunits in unicellular organisms does not always lead to inviability; examples are seen in various fungal species, including Aspergillus nidulans, Neurospora crassa, Schizosaccharomyces pombe, or Sacharomyces cerevisiae [34,35]. Cullin deneddylation is performed only when CSN5 resides in an intact CSN, attached to the CRL [16-18,21]. In human, CSN-CRL interactions lead to a line of conformational changes within the CSN complex, starting by attachment of CSN4 to the cullin subunit, triggering rearrangements in CSN6, and finally priming a glutamate 104 residue in CSN5 for deneddylation [36,37]. Recently, CSN5i-3, a specific and orally available inhibitor of the human CSN5, was selected via a high-throughput screen for small molecule inhibitors [26]. CSN5i-3 interferes with the UPS by blocking the deneddylation of a subset of CRLs and therefore suggests them as druggable targets.

The CSN complex also regulates CRLs in a non-catalytic manner through steric clashes that inhibit the recognition of substrates for ubiquitination by CRL substrate receptors, and by preventing the association of CRLs with Ub E2 enzymes, which are required to ubiquitinate these substrates (Figure 1A, right) [36,38]. When it comes to complex integrity, most CSN subunits normally exist in a stable complex, whereas CSN5 is unique in its distribution both as part of a CSN holocomplex and in free form (CSN5-f) [39,40]. CSN5-f is a pro-proliferative factor [41] that interacts with the cyclin-dependent kinase Cdk2 [42], mediates nuclear export followed by degradation of the CDK inhibitor p27, and interacts with activator protein 1 (AP-1) to mediate proliferation [43].

Not all of these functions of CSN5-f/CSN are conserved across phyla. Indeed, the most diverged CSN complex was found and characterized in the budding yeast S. cerevisiae [44-47]. This complex excludes orthologues for CSN3 and CSN8 [48]. The orthologue of CSN6 (aka Csi1) is diverged and lacks the characteristic amino acid sequence for MPN domain [44]; the core subunit CSN4 is absent and replaced by the paralogous subunit within the 19S lid, Rpn5 [45]. In this manuscript, we describe a sensitive fluorescence readout assay, suitable for biochemical assessment of cullin deneddylation by CSNs from distinct organisms, such as Homo sapiens and S. cerevisiae. We also exhibit that the $S$. cerevisiae Csn5 is inhibited by CSN5i-3, an inhibitor that targets the human orthologue. Altogether, we demonstrate that despite the diverged composition, the architecture and enzymatic activity of the CSN cullin deneddylase are highly conserved from yeast to human.

\section{Materials and Methods}

\subsection{Strains and Plasmids}

All plasmids were isolated from Escherichia coli DH5 alpha cells using an alkaline lysis plasmid preparation method. Plasmids were either used in previous research or cloned for this study as indicated in Table S1. All single deletion S. cerevisiae mutants were purchased or obtained as specified in Table S2. The double mutant of $\Delta c s n 5 / \Delta r u b 1$ was formed by mating and sporulation between the single mutants. 


\subsection{Plasmid Cloning}

Cdc53/yCul1 truncation mutants were performed through PCR amplification of CDC53 from genomic DNA using primers (Table S3), followed by DNA sequencing. The amplified DNA was subcloned by recombination into the Yeplac181 plasmid including the alcohol dehydrogenase1 (ADH1) promoter, Regulator of G-Protein Signaling 9 (RGS), and 8His tags (EP153), generating plasmids EP172, EP237, EP238, and EP247.

Subcloning of Rub1 was performed through PCR amplification using specific primers (Table S3). The PCR product was cloned by recombination downstream to ADH1 promoter and a Green fluorescent protein (GFP) tag, generating plasmid EP233.

\subsection{Growth Conditions}

The various yeast strains were grown in a rich YPD medium (yeast extract 1\%, peptone $1 \%$, dextrose $2 \%$ ), unless specified otherwise. Plasmids were maintained by culturing the plasmid-containing strains in a selective synthetic complete medium based on a yeast nitrogen base (YNB) supplemented with ammonium sulfate, in which a complete mixture of amino acids supplements each of the commonly encountered auxotrophies. The various inhibitors (cycloheximide, MG132, and CSN5i-3) were dissolved in dimethyl sulfoxide (DMSO) before being added directly to the growth medium as indicated.

\subsection{Native Protein Extraction}

Cells were cultivated for 24-48 h then washed twice with DDW and re-suspended in two volumes of Y-cell lysis buffer (Sigma Aldrich, Rehovot, Israel). For extraction, 0.5-mm sized zirconia beads were added followed by vortexing the samples for $1 \mathrm{~min}, 10$ times, with $1 \mathrm{~min}$ intervals on ice. Native lysates were clarified by centrifugation at $16,000 \times g$ for 10 min at $4{ }^{\circ} \mathrm{C}$ and transferred to a clean tube.

\subsection{Calmodulin-Based Affinity Purification of the CSN}

S. cerevisiae CSN purification was performed through the affinity tagged version of Csn10, harboring a Calmodulin Binding Peptide (CBP) at the $C$ terminal as previously described [45]. The elution was used for immunoblotting or subjected for CSN activity tests.

\subsection{Immunoblotting}

Grown cultures were harvested in trichloroacetic acid (TCA) as previously described [45]. Following the extractions, samples were resolved by SDS-PAGE and transferred to a nitrocellulose membrane for immunoblotting as presented in the figure legends. Experiments were repeated at least three times and a representative image is shown.

\subsection{Purification of the Substrate by Ni-NTA Affinity Chromatography}

Ni-NTA beads were washed twice by Y-cell lysis buffer (Sigma-Aldrich, Rehovot, Israel), then washed twice with Tris-buffered saline (20 mM Tris, pH 7.5. $150 \mathrm{mM} \mathrm{NaCl})$ complemented by $0.1 \%$ Tween 20 before added to native protein lysate of cells co-expressing 8 His-yCul1 and GFP-Rub1. Samples were placed on a rotator overnight at $4{ }^{\circ} \mathrm{C}$, and then centrifuged in $3000 \times g$ for a minute. Elutions were used for immunoblotting, fluorescent readout in a microplate reader (Biotek Synergy HT, Winooski, VT, USA) (excitation: $485 \mathrm{~nm} / 20$, emission: $528 \mathrm{~nm} / 20$ ), or subjected for CSN activity assay. 


\subsection{Fluorescence Microscopy}

Early logarithmic phase cultures $\left(\mathrm{OD}_{600} \mathrm{~nm}=0.8-1.0\right)$ were centrifuged and washed once with phosphate buffer saline (PBS) before the addition of dyes (BODIPY or FM464). Differential interference contrast (DIC) and fluorescence of cells were evaluated by a microscope (NIKON Eclipse E600, Tokyo, Japan) and photographed according to Sinha et al., 2020 [48].

\subsection{Ergosterol Extraction and Analysis}

The evaluation of ergosterol quantity in yeast cells was performed as previously described [48].

\subsection{Endogenous Oxidative Stress Measurements}

Endogenous reactive oxygen species (ROS) was measured by fluorescence following treatment with $2^{\prime}, 7^{\prime}$-dichlorofluorescein diacetate (DCFDA) (Sigma-Aldrich, Rehovot, Israel), which was directly added the cultures as described [49].

\subsection{CSN Activity Assay}

Total extracts of yeast cells expressing 8His-Cul1-GFP-Rub1 substrate were mixed with either human CSN complex (Protein Center, Ramat Yohanan, Israel https:/ / proteasome. net/; accessed on 20 December 2018) or with total cell extracts of wildtype yeast cells (harboring the endogenous yeast CSN complex). CSN activity was performed on a rotator for $30 \mathrm{~min}$ at room temperature. At the next step the substrate was affinity purified for $45 \mathrm{~min}$ on Ni-NTA resin at $4{ }^{\circ} \mathrm{C}$ followed by three washes with TBST $\times 0.5$ and elution from the resin with $250 \mathrm{mM}$ imidazole. The fluorescence readout of eluted proteins was quantified by a plate reader (excitation: $485 \mathrm{~nm} / 20$, emission: $528 \mathrm{~nm} / 20$ ). Fluorescent values were compared with a CSN-free control experiment. CSN activity was calculated as the ratio between the residual fluorescence in the CSN-containing assay divided by the control fluorescence.

\section{Results and Discussion}

Although Rub1 is not required for the S. cerevisiae viability [50], the neddylation pathway in this organism is highly conserved, including a viable replacement of the $S$. cerevisiae Rub1 with the mammalian NEDD8 that can modify Cdc53/yCul1 [51]. Molecular modeling suggests evolutionary conservation of the binding sites for either ATP or NEDD8/Rub1 in the E1 enzyme (NAE1) of human and yeast, also reflected by superimposition of MLN4924 (Pevonedistat), a selective inhibitor for NAE1 (Figure 1B; Table S4). Unlike the conserved neddylation pattern, CSN composition is more diverged (Table 1; Supplemental Alignment) [37,52-54]. Indeed, the S. cerevisiae CSN subunits cannot be replaced by their orthologues [45]. Yet, considering cullin deneddylation, S. cerevisiae and human CSN complexes demonstrate cross-species enzymatic activity: Purified CSN complexes from each origin can hydrolyze NEDD/Rub1 from CRLs of the other organism in total cells extracts [44,55]. According to the previously described orientation (Figure 1C, left [26]), we predicted the binding-conformation of the small molecule ligand, CSN5i-3, to the MPN+/JAMM motif of the S. cerevisiae Csn5 (Figure 1C, right). The superimposition confirmed high conservation of the CSN MPN+/JAMM motif across phyla. Indeed, the predicted structure of $S$. cerevisiae Csn5 shows a high similarity to four published human CSN5 structures (Figure S1, Supplemental Alignment). 
Table 1. Sequence identity between the H. sapiens and S. cerevisiae orthologues CSN subunits.

\begin{tabular}{|c|c|c|c|c|c|c|}
\hline $\begin{array}{l}\text { H. sapiens } \\
\text { vs. } \\
\text { S. cerevisiae }\end{array}$ & $\begin{array}{c}\text { CSN1 } \\
\text { vs. } \\
\text { Csn11 } \\
{\left[{ }^{*} 1\right]}\end{array}$ & $\begin{array}{l}\text { CSN4 } \\
\text { vs. } \\
\text { Rpn5 } \\
{\left[{ }^{*} 2\right]}\end{array}$ & $\begin{array}{l}\text { CSN5 } \\
\text { vs. } \\
\text { Csn5 } \\
{\left[{ }^{*} 3\right]}\end{array}$ & $\begin{array}{l}\text { CSN6 } \\
\text { vs. } \\
\text { Csi1 } \\
{\left[{ }^{*} 4\right]}\end{array}$ & $\begin{array}{l}\text { CSN7 } \\
\text { vs. } \\
\text { Csn9 } \\
{\left[{ }^{*} 5\right]}\end{array}$ & $\begin{array}{c}\text { CSN2 } \\
\text { vs. } \\
\text { Csn10 } \\
{\left[{ }^{*} 6\right]}\end{array}$ \\
\hline $\begin{array}{c}\text { Sequence } \\
\text { identity (\%) }\end{array}$ & $16 \%$ & $\begin{array}{c}100 \% \text { to the } 19 S \\
\text { lid Rpn5 }\end{array}$ & $39.3 \%$ & $15 \%$ & $23.4 \%$ & $20 \%$ \\
\hline Coverage (\%) & $85 \%$ & $100 \%$ & $47 \%$ & $82 \%$ & $77 \%$ & $84 \%$ \\
\hline GMQE & 0.38 & 0.76 & 0.25 & 0.5 & 0.39 & 0.12 \\
\hline QMEAN & -5.57 & -2.61 & -0.62 & -4.08 & -1.2 & -4.7 \\
\hline $\begin{array}{c}* * \text { Confidence } \\
(\%)\end{array}$ & $99.7 \%$ & & & $98.0 \%$ & & $100 \%$ \\
\hline
\end{tabular}

[*1] Built on RPN7 crystal structure (PDB ID:4CR2, [56]). [ $\left.{ }^{*} 2\right]$ CSN4-Rpn5 is identical to the proteasomal Rpn5 subunit. Based on the Rpn5 crystal structure (PDB ID:5MPD, [53]). [*3] Built on CSN5 crystal structure (PDB ID:4D18, [37]). [*4] Built on CSN6 crystal structure (PDB ID:4D10, [37]). [*5] Built on A. thaliana CSN7 crystal structure (PDB ID: 3CHM, [54]). [*6] Built on CSN2 crystal structure (PDB ID:6R7N, [57]). Global model quality estimation $(\mathrm{GMQE})>0$ is an estimator that combines properties from the target-template alignment and the template structure [58]. The qualitative model energy analysis $(\mathrm{QMEAN})<(-4)$ provides estimation for the "degree of nativeness" of the structural features in the model [59]. ** Confidence values were calculated for Csn11, Csi1, and Csn10 through Phyre ${ }^{2}$ [60]. Confidence represents the probability $(0-100 \%)$ for true homology between the aligned sequences and their templates (see "Supplemental Alignment" for additional information).

\subsection{S. cerevisiae Harbors a Highly Conserved Enzymatic Core Complex}

The C-terminal domain of CSN6 has an indispensable role in maintaining the full integrity of the CSN complex, even in a truncated mutant lacking the $\mathrm{MPN}^{-}$domain [44]. These data were confirmed by Lingaraju et al., 2014 [37], who resolved the crystal structure of the human CSN in a resolution of 2.8 $\AA$. The structure elucidated a horseshoe-shaped molecular architecture, formed by the N-terminal of PCI subunits, surrounding a helical bundle built from C-terminal of all subunits, with both MPN domains of CSN5 and CSN6 located above it. Unlike the C-terminal of CSN6, which interacts with all other subunits, CSN5 creates fewer interactions, which could indicate on a more dynamic nature $[39,40]$. In a previous study, we identified the $S$. cerevisiae Csi1 as a diverged CSN subunit, displaying homology with the C-terminal of the canonical Csn6 (a.k.a. S6CD), but lacking the MPN domain. To confirm that Csi1 also interacts with various subunits and maintains the CSN architecture, we approached the protein-fragment complementation assay (PCA) [61]. In this assay, the integrity of $S$. cerevisiae cytosine deaminase (FCY1) fragments, each of which is attached to a different protein, was used as a reporter that allowed for a survival assay by deaminating cytosine to the essential uracil. The results revealed direct interactions between Csi1 and three CSN subunits: Csn5/CSN5, Csn9/CSN7, and Rpn5/CSN4 (Figure S2). To complete the picture, a calmodulin-based affinity pulldown of a chromosomal integrated Csn10/CSN2 TAP-tagged at the C-terminal (CBP followed by two immunoglobulin Gbinding domains of protein A) revealed an internal interaction between Csn10/CSN2 and both CSN9/Csn7 and Rpn5/CSN4, even in the absence of Csn5 (Figure 2A,B). The above suggests that similarly to CSN6 in canonical CSN complexes, the yeast Csi1 is a central element in the complex integrity, while Csn5 shows more freedom. 
A

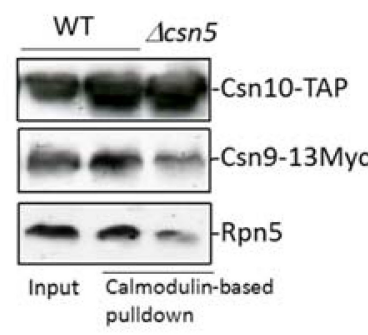

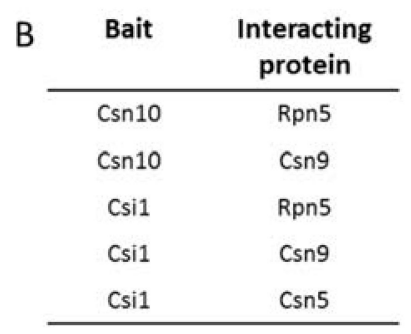

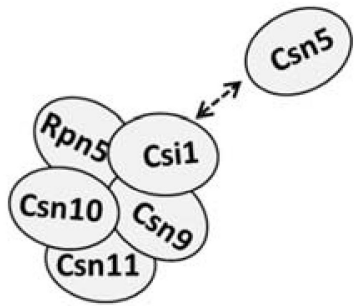

C

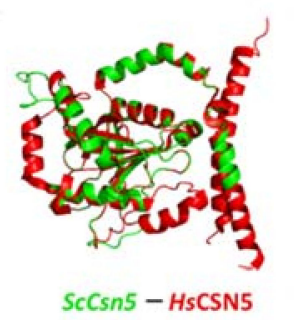

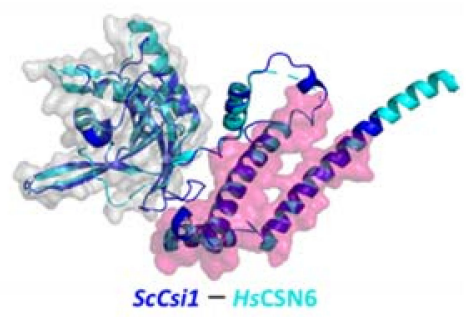

D

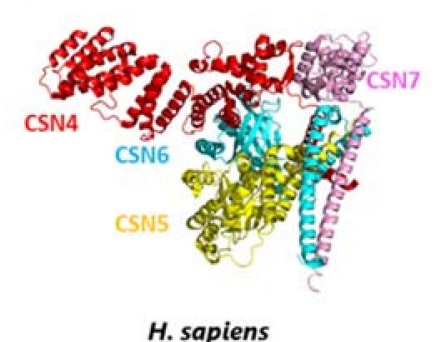

H. sapiens

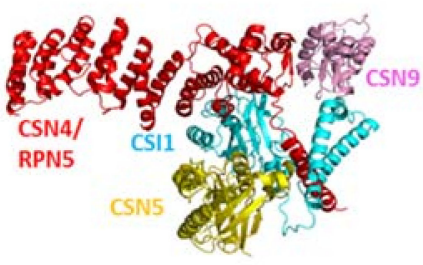

S. cerevisiae

COP9 signalosome - deNEDDylase core complex

Figure 2. Interactions between the S. cerevisiae CSN subunits. (A) The pulldown of CSN10-TAP through calmodulin affinity resin from wildtype and $\Delta c s n 5$ mutant cells used to evaluate subunit interactions through immunoblotting for Rpn5 (by Rpn5 antibodies) and Csn9-13Myc (by Myc antibodies). (B) A summary of the findings in Figure 2A and Figure S2. (C) Superimposition of the S. cerevisiae Csn5 (green) and Csi1 (blue) homology models with their corresponding H. sapiens CSN5 and CSN6 template structures (Red and cyan respectively, PDB ID 4D10). Gray and pink surface representation is shown for the CSN6/Csi1 MPN domain (residues 35-145 in CSN6) and S6CD domain (residues 215-295 in CSN6), respectively. (D) Empirical 3D structure of the human and S. cerevisiae CSN deNEDDylase core complexes. S. cerevisiae homology models were built using Swiss-Model for Csn5, CSN4/Rpn5, and CSN7/Csn9, or by Phyre ${ }^{2}$ for Csi1, as described in Table 1 and in the Supplemental Alignment. Note that residues that are not aligned with the sequence of the template are not shown in this predicted comparative model.

Interestingly, molecular modeling of Csi1 on available structures of the human orthologue of CSN6 by Swiss-Model suggested an N-terminal MPN structural fold. Since Swiss-Model is highly reliant on the correct template provided for modeling, we ran structure prediction on Csi1 using Phyre ${ }^{2}$. Interestingly, using this modeling tool, the closest model for Csi1 was found as PDB ID 5A5T of the human eIF3F $(98.0 \%$ confidence, $13 \%$ sequence identity), one of the two MPN subunits of the eIF3, which is in fact a paralogue of CSN6/Csi1. CSN6 appeared second on the Phyre ${ }^{2}$ list, with $97.5 \%$ confidence and 15\% sequence identity. We used CSN6 (Figure 2C) and eIF3F (Figure S3A) as templates to predict Csi1 structure. The superimposition of Csi1 (dark blue) with either CSN6 or eIF3F (light blue) revealed a possible MPN fold at the N-terminal areas of the $S$. cerevisiae Csi1. This estimated structure could not be predicted in the past, due to poor structural data [44]. The above suggests that the MPN dimer (CSN5-CSN6 dimer) could be highly conserved. Given these considerations, we approached a modeling method to confirm the high conservation of the deneddylase core complex, composed of Csn4, Csn6, and Csn5 [37] (Figure 2D and Figure S3B). Overall, this implies that the CSN deneddylase core complex may be more conserved than estimated. Nevertheless, the presence homology modeling is partially based on low coverage (Table 1; Supplemental Alignment), hence, additional structural studies are required. 


\subsection{Utilizing the S. cerevisiae Neddylation Pathway to Develop a Fluorogenic CSN Substrate for In Vitro Studies}

The conserved CSN deneddylase core complex (Figures 1C and 2D) and the crossspecies enzymatic activity $[44,55]$ have led to the speculation that yeast can be approached instrumentally as a tool for developing a general substrate for CSN activity assay. The S. cerevisiae genome encodes for three cullin proteins (yCul1/Cdc53, Cul3, and Cul4/Rtt101), each of which serves as a building block for the assembly of multi-subunit CRLs [62-65]. The yCul1-based CRL is an archetype of the family, also known as the Skp1 Cul1 F-box (SCF) [64]. We selected yCul1 to evaluate if the endogenous neddylation cascade tolerates the modification of its overexpressed version by a co-expressed GFP-Rub1, in a double mutant yeast strain, lacking CSN activity and endogenous Rub1 (Figure 3A). We speculated that such a modified cullin could fit as a substrate for CSN from various origins and would be valuable for a quantitative understanding of CSN biochemical properties. Because yCul1 is a large protein, essential for yeast viability, we wanted to select a protein size with a minimal effect on yeast vitality. With this in mind, we designed a number of yCul1 truncation mutants, all of them included the neddylation site, Lys 760, located at the C-terminal domain of yCul1 [66], yet shorter in the N-terminal substrate recognition domain. For affinity purification purposes, each of the mutants included the $\mathrm{N}$-terminal 8 His tag for the binding of Ni-NTA affinity resin and withstood extensive washing to remove non-specifically bound proteins (Figure 3B, top). Both the ability to be modified by endogenous Rub1 and recognition by the CSN were determined for each truncated mutant by immunoblotting in wildtype $\Delta c s n 5$ or $\Delta r u b 1$ mutant strains, as summarized in the table (Figure 3B, right).

Each of the truncation mutants was ectopically expressed in a multi-copy plasmid under the control of $A D H 1$ promoter. With the distinction of $\mathrm{C} 192$, all of them were expressed in the cells, and sizes larger than C377 were found neddylated by endogenous Rub1 in $\Delta \operatorname{csn} 5$ cells (data not shown). Since yCul1 is a key cell cycle regulator [67], we evaluated if expression of the truncated mutants interferes with growth or morphology. Indeed, ectopic expression of C293 led to very small-sized yeast colonies that could not be cultivated in broth medium or transferred to fresh plates from the transformation plates. Examination of cell morphology by microscope suggested severe cell cycle defects (Figure 3B, bottom). Although the truncation mutants did not provide a practical advantage to the assay, they can still be useful, especially given the dominant negative activity of C293. This mutant lacks the N-terminal arm of yCul1 that is involved in the selection of SCF substrates, and could thus be suggested as an original way to identify additional SCF substrates that have not yet been identified. Note that both FL815 and C548 showed a similar neddylation ratio upon logarithmic growth (Figure S4A). The C548 truncated mutant was generated according to Scott et al., 2010 [66], which produced a similar mutant (a.k.a. "C+"), for in vitro yCul1Skp1 binding assays. Their results showed that C548/C+ cannot interact with the adaptor protein Skp1. Knowing that SCF assembly (i.e., the assembly of yCul1 with Skp1 and Rbx1) is required for vitality, it was surprising that overexpression of this mutant did not interfere with the SCF assembly by causing a cell cycle arrest. Contrary to expectations, the C548/C+ even presented effective yCul1 neddylation in $\Delta c s n 5$ (Figure S4, top). We assumed that at least in vivo, the $\mathrm{C} 548 / \mathrm{C}+$ is sufficient for the Skp1-yCul1 interaction. This possibility is supported by the finding of Kurz et al., 2005, which showed that Skp1 is necessary, to a certain extent, for neddylation [68]. We speculated that dissimilarities between in vitro and in vivo data are due to other protein-protein interactions, either through other complex counterparts or by assisting chaperons. However, since C548 showed slight abnormal cell morphology (Figure 2B) and had no advantage compared with FL815, we eventually approached the full size of yCul1, FL815, to standardize the cullin deneddylation assay. 
A
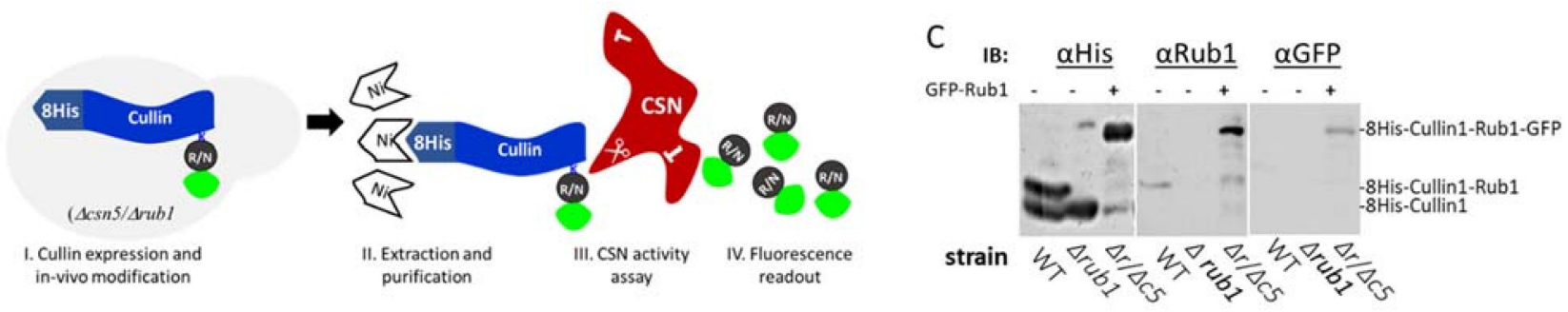

B

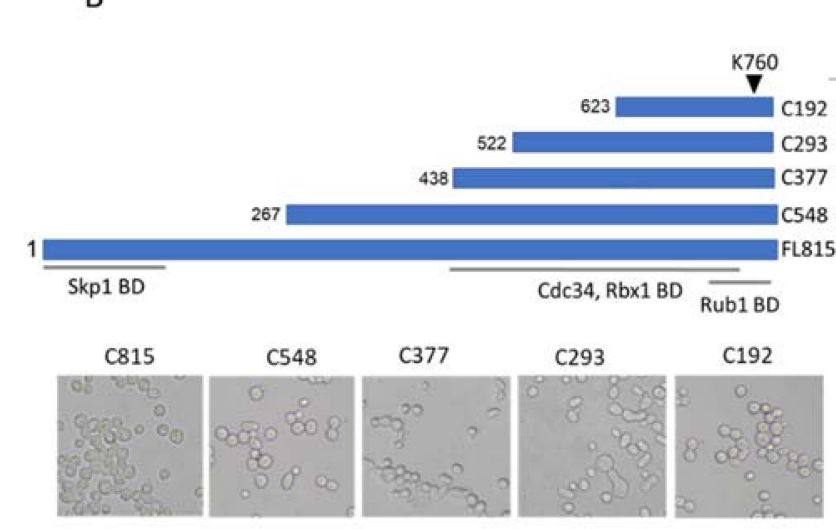

\begin{tabular}{|c|c|}
\hline $\begin{array}{c}\text { Cullin } \\
\text { NEDDylation }\end{array}$ & $\begin{array}{c}\% \text { of abnorma } \\
\text { cells }\end{array}$ \\
\hline$(-)$ & 0 \\
\hline$(-)$ & 41 \\
\hline$(-) /+$ & 10 \\
\hline+ & 6 \\
\hline+ & 1 \\
\hline
\end{tabular}

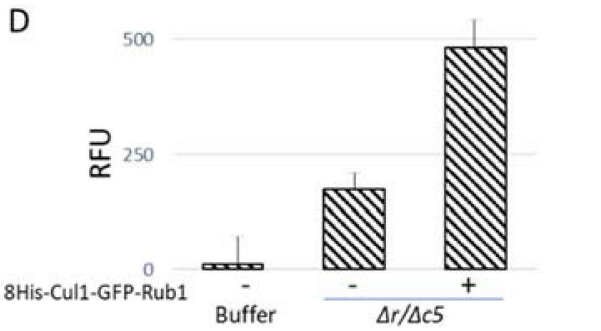

Figure 3. Designing a general substrate for a CSN cullin deneddylase readout assay. (A) Assay scheme: 8His-Cullin (yCul1) and GFP-Rub1/Nedd8 $(\mathrm{R} / \mathrm{N})$ are overexpressed in $\Delta c s n 5 \Delta r u b 1$ mutant cells, and become covalently attached to each other through the endogenous neddylation cascade of enzymes. Next, the 8His-yCul1-GFP-Rub1 conjugates (e.g., substrate) are affinity purified through Ni-NTA resin. These substrates are added to CSN or CSN-containing extracts (e.g., enzyme), which eventually cause the hydrolysis of GFP-Rub1 (e.g., product) that is collected for fluorescence evaluation. (B) Various mutants of yCul1, all of which bear the neddylation specific residue (K760) and an N-terminal 8His tag. Terminology is according to the number of amino acids in each of the mutants. Rub1, Rbx1, and Skp1 binding domains (BD) are illustrated at the bottom. The ability of each yCul1 form to be modified by Rub1 (neddylation) is indicated by + or (-). Transformant $\Delta c s n 5 \Delta R u b 1$ mutant cells bearing the yCul1 truncations were collected directly from the agar plates and cell morphology was examined by light microscopy. Cells with abnormal morphology (enlarged or elongated) were counted, and the percentage of cells showing atypical morphology was summarized (top, right) or shown (bottom). (C) The ability of endogenous neddylation enzyme to modify 8 His-yCul1 by GFP-Rub1 was evaluated. Wildtype (wt) $\Delta r u b 1$ and $\Delta c s n 5 \Delta r u b 1(\Delta r / \Delta 5)$ expressing the fluorogenic substrate were grown in selective medium. Neddylation of the full length 8His-yCul1 (FL815) was analyzed by immunoblotting with antibodies for yCul1, 6His, and GFP. (D) Native protein extracts were linked to Ni-NTA resin, eluted, and fluorescent readout was detected by a plate-reader and counted in "relative fluorescent units" (RFU). Notably, cells expressing FL815 and GFP-Rub1 show high fluorescence values compared to naïve cells or buffer controls.

To confirm that the expression of GFP-Rub1 improves the neddylation properties of the co-expressed 8His-yCul1, plasmids were co-transformed into $\Delta c s n 5 \Delta r u b 1$ cells. Immunoblotting for anti-6His (to recognize the 8His-yCul1), anti-GFP, or anti-Rub1 (to recognize GFP-Rub1) revealed a protein at the same marker size as 8His-yCul1-Rub1GFP, suggesting that the intrinsic $S$. cerevisiae neddylation pathway is sufficient for the modification of overexpressed $8 \mathrm{His}$-yCul1 by the co-expressed N-terminally GFP-tagged version of the modifier (Figure 3C). Similarly, the affinity purification of 8 His-yCul1 via Ni-NTA followed by imidazole elution led to a high fluorescence readout compared to imidazole containing buffer, or to mock purification using naïve wildtype cell extracts (Figure 3D). In order to develop a readout assay, in which the fluorogenic product (i.e., GFP-Rub1) is efficiently hydrolyzed from 8His-yCul1, we repeated the purification without eluting the substrate from the resin. Accordingly, S. cerevisiae CSN was purified from wildtype cells, expressing a chromosomal Csn10-TAP and kept attached to the calmodulin resin. Deneddylation was carried out by mixing resin-attached enzymes with resin-attached 8 His-yCul1-GFP-Rub1 substrates for $20 \mathrm{~min}$ at $30{ }^{\circ} \mathrm{C}$. Following the assay, the beads were washed to remove the released GFP-Rub1 product, and the residual fluorescence 
of the substrate while still attached to the beads was measured and compared with the fluorescence of the experiment buffer, CSN alone, or the untreated 8His-yCul1-GFP-Rub1 substrate (Figure $4 \mathrm{~A}$ ).

A
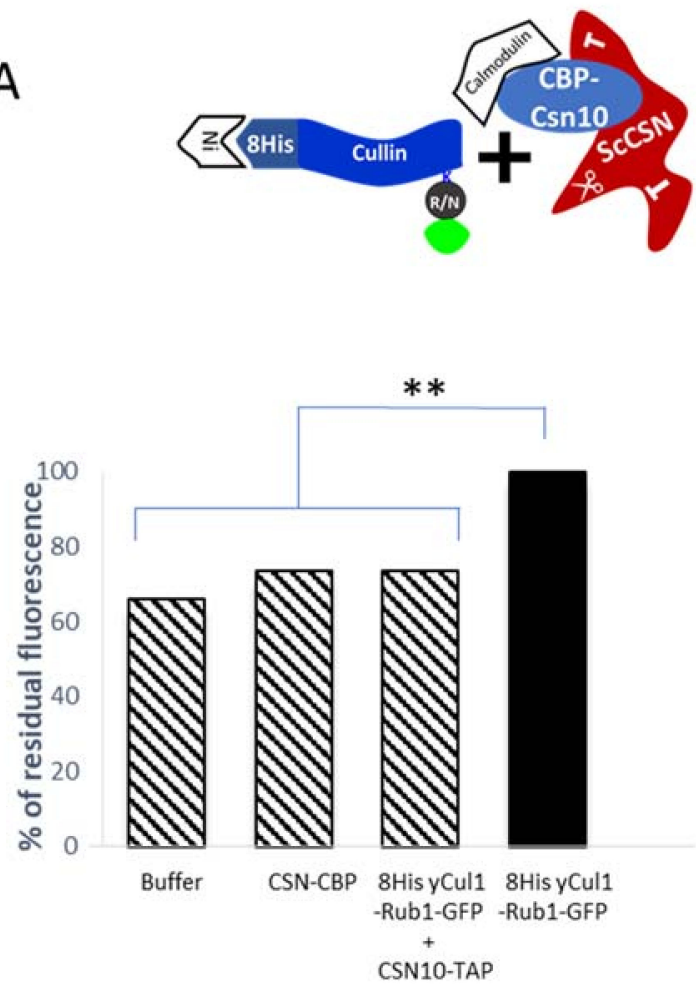

B
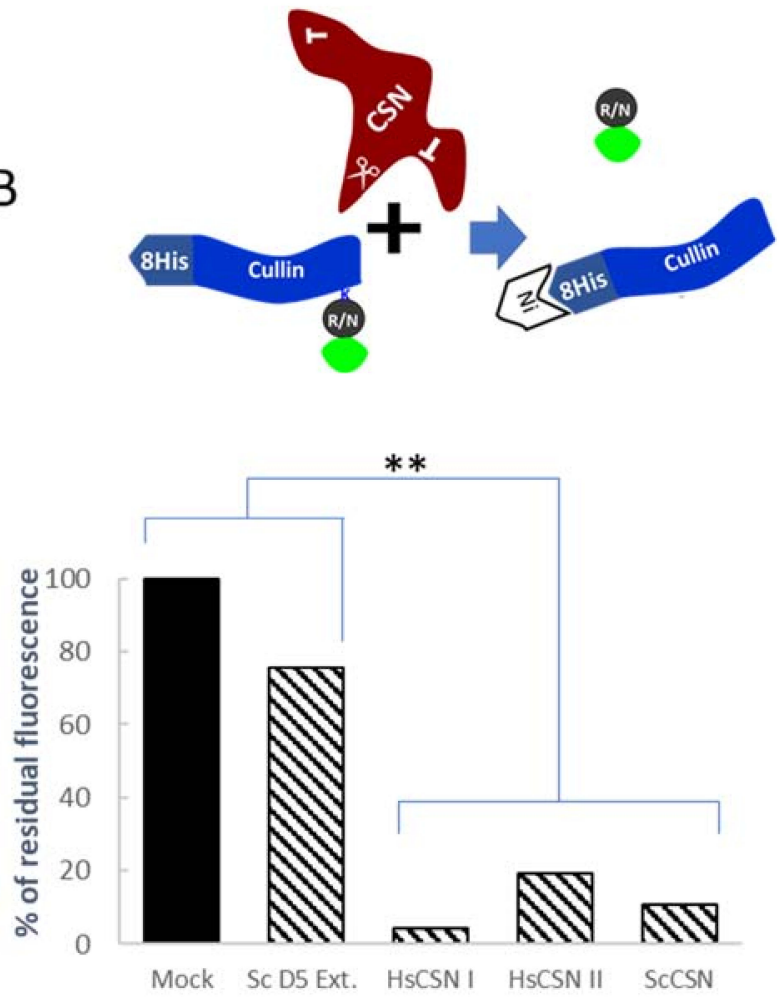

Figure 4. Using the S. cerevisiae fluorescent substrate to evaluate human CSN activity. (A) Ni-NTA resin (Ni)-attached substrate (8His-yCul1-GFP-Rub1) was mixed with calmodulin resin attached to CBP-Csn10 CSN complexes (ScCSN) for 20 min before evaluating the fluorescent readout. Readout of the buffer, or substrate-free CSN resin were used as controls. The residual fluorescent of the substrate in the CSN-included assay (lane 3) is compared to the total fluorescence in the enzyme-free experiment (lane 4). (B) Crude extract of $\Delta c s n 5 \Delta r u b 1$ cells expressing 8His-yCul1-Rub1-GFP exposed to purified human CSN from individual purification events (CSN I, CSN II) and to wildtype S. cerevisiae extract (ScCSN) for $30 \mathrm{~min}$ at $30{ }^{\circ} \mathrm{C}$. Following the assay, the substrate was linked to Ni-NTA resin and fluorescent readout was evaluated, compared with controls (in black): Substrate treated by buffer (mock), or with $\Delta c s n 5$ yeast extracts (Sc D5 ext.). Results were statistically verified by one-way ANOVA followed by Tukey HSD Test $(n>3) .{ }^{* *}$ represents $p<0.01$.

The expected result was a decline in fluorescence of the resin-attached substrate, co-treated with the CSN. Although repeated in three independent experiments, the high background and only small differences in the relative fluorescent units (RFU) compared to controls indicated the futility of this assay as a CSN readout assay in the long term. Among all other conditions that were evaluated, we found the strategy of adding resin-free CSN to a crude extract of $\Delta c s n 5 \Delta r u b 1$ cells expressing the 8 His-yCul1-GFP-Rub1 substrate as the best option (Figure 4B). In this experimental setting, the 8His-yCul1-GFP-Rub1 substrate was subjected for Ni-NTA purification only following the experiment. CSN activity was calculated as the ratio between the fluorescence of a fixed amounts of substrate exposed to the CSN, or to buffer used as a control. Accordingly, substrates that had been pretreated with human CSNs were compared to the buffer-treated substrates, and crude extracts of $S$. cerevisiae wildtype cells (containing endogenous CSNs) were compared to crude extracts of $S$. cerevisiae $\Delta c s n 5$ mutant cells lacking CSN activity (Figure $4 \mathrm{~B}$ ). The low fluorescence of CSN-containing experiments compared to the controls suggested a highly 
detectable cullin deneddylase activity of CSN complexes from diverged organisms. In conclusion, we were able to develop a general fluorescent substrate, available for in vitro CSN deneddylation activity. Given that S. cerevisiae 8His-yCul1-GFP-Rub1 is an effective substrate for complexes from the most distinct organisms, it may serve as a universal substrate for evaluating the activity of CSN found in most, if not all, eukaryotes.

\subsection{CSN5i-3 Targets CSN5/Csn5 from Diverged Eukaryotic Sources}

The predicted docking position of CSN5i-3 indicates that the behavior of this small molecule in the human or S. cerevisiae CSN active site is alike at the atomic level (Figure 1C); thus, CSN5i-3 might be useful for CSN studies in S. cerevisiae. To evaluate this supposition, we approached $\Delta p d r 5$ (pleiotropic drug resistant), a mutant yeast strain that allows resistance to an array of drugs to be overcome, and therefore promoting the entry of CSN5i-3 into cells. As an initial proof of concept, the concentration that most effectively inhibits CSN activity in $\Delta p d r 5$ cells was selected. Accordingly, cells were grown to the early logarithmic phase in a glucose-rich YPD media, before the addition of CSN5i-3 for the specified times (Figure 5A).

A

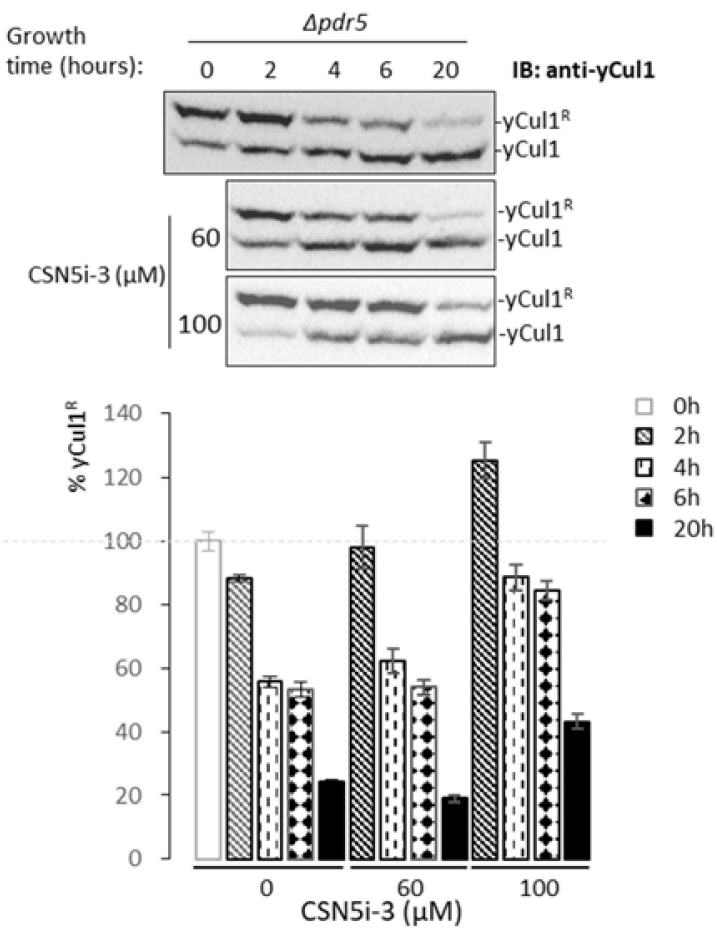

B

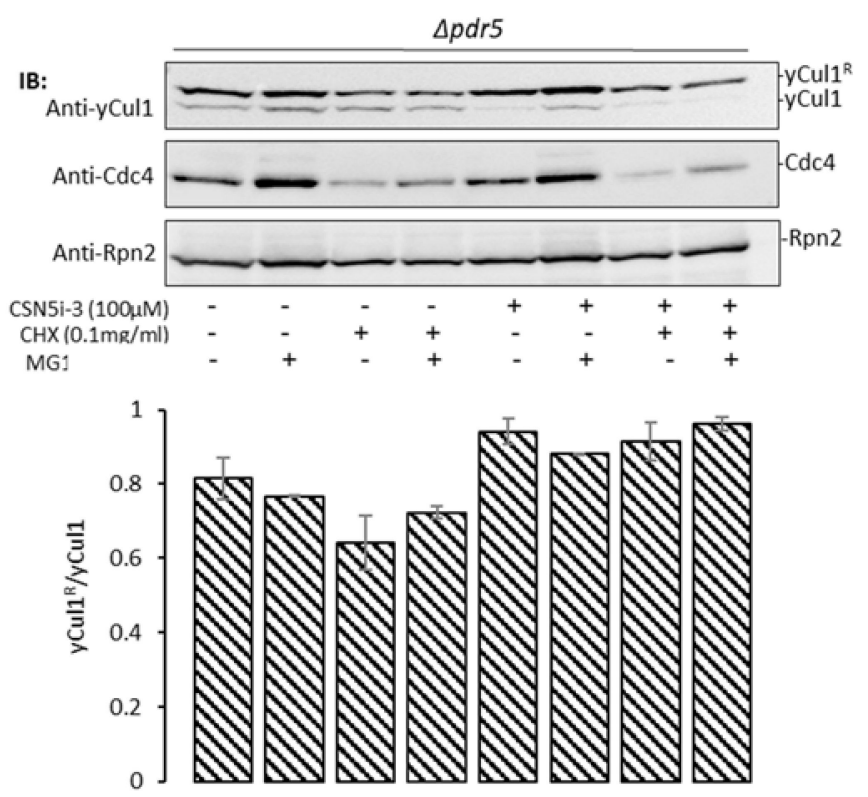

Figure 5. The human Csn5 inhibitor CSN5i-3 is compatible to S. cerevisiae. (A) Logarithmic $\Delta p d r 5$ cells were treated with CSN5i-3 $(0,60$, and $100 \mu \mathrm{M})$ for indicated times $(0-20 \mathrm{~h})$. The neddylation status of yCul1 was calculated through IMAGEJ from three independent experiments, shown as \% of neddylation from the starting 0-h time-point (bottom). (B) $\Delta p d r 5$ cells at the early log phase were treated with CSN5i-3 $(100 \mu \mathrm{M})$, cycloheximide (CHX) $(0.1 \mathrm{mg} / \mathrm{mL})$, and MG132 (50 $\mu \mathrm{M})$ to assess the inhibition effect of CSN5i-3 on deneddylation. Representative immunoblots of yCul1 show the effect of the different treatments on $\mathrm{yCul1} / \mathrm{yCul1}^{\mathrm{R}}$ ratio with the short-lived protein Cdc4 as control for CHX and MG132 inhibition treatments. Rpn2 expression is presented as a loading marker.

Notably, $100 \mu \mathrm{M}$ of CSN5i-3 was compared with the highest concentrations that was used for Csn5 targeting in human cells [26]. The effect of CSN5i-3 was studied by evaluating if the treatment led to a higher neddylation status. The immunoblots obtained show that CSN5i-3 has an effect that decreases overtime, only at concentrations higher than $60 \mu \mathrm{m}$ (Figure 5A). Effective inhibition of yCul1 deneddylation was seen upon incubation 
with $100 \mu \mathrm{M}$ of the inhibitor for $2 \mathrm{~h}$. To confirm that the change in yCul1 neddylation ratio was not due to modulation in protein expression/stability, the ratio of neddylated to free yCul1 was assessed following cells treatment by cycloheximide ( $\mathrm{CHX})$ to inhibit protein expression, or MG132 to inhibit proteasomal degradation. Immunoblots showed that CSN5i-3 causes accumulation of yCul1 neddylation ( $30 \%$ difference) upon co-treatment of CHX with CSN5i-3 (Figure 5B, lane 3 vs. lane 7), altogether suggesting that CSN5i-3 had effectively inhibited the deneddylation of $S$. cerevisiae yCul1, hence, allowing the use of CSN5i-3 for studying S. cerevisiae CSN activity in vivo, in various environmental or metabolic conditions.

Our previous findings revealed metabolic and induced accumulation of ROS as a molecular switch-off of the neddylation cascade. Indeed, the addition of hydrogen peroxide $\left(\mathrm{H}_{2} \mathrm{O}_{2}\right)$ led to a dramatic decrease in cullin neddylation and the accumulation of cullin-free Rub1 [49]. The modulation of yCul1 neddylation status in an oxidative environment from highly to slightly modified may indicate CSN activity during oxidative stress. To evaluate this possibility, we treated $\Delta p d r 5$ cells with $\mathrm{H}_{2} \mathrm{O}_{2}$ and evaluated if co-treatment with $100 \mu \mathrm{M}$ of CSN5i-3 altered yCul1 neddylation status. Unexpectedly, unlike wildtype, cullin neddylation status in $\Delta p d r 5$ cells was not sensitive to $\mathrm{H}_{2} \mathrm{O}_{2}$ (Figure S5). Due to these findings, the efficacy of various concentrations of CSN5i-3 was evaluated in wildtype logarithmic cells as well. As expected, the dose of CSN5i-3 that targets Csn5 in wildtype cells and leads to elevated yCul1 neddylation status was higher $(200 \mu \mathrm{M})$ than in the $\Delta p d r 5$ mutant $(100 \mu \mathrm{M})$ (Figure 6A compared with Figure 5A). We used this concentration to assess if CSN activity is maintained in an oxidative environment. For this purpose, logarithmic wildtype cells were treated by $\mathrm{H}_{2} \mathrm{O}_{2}$ for 10 or 30 min following the addition of CSN5i-3 $(200 \mu \mathrm{M})$. Indeed, the addition of $\mathrm{H}_{2} \mathrm{O}_{2}$ led to increased performance of non-neddylated yCul1 (Figure 6B, lane 2). Yet, the pretreatment with CSN5i-3 slowed down the effect of $\mathrm{H}_{2} \mathrm{O}_{2}$, which was reflected in a smaller amount of non-neddylated yCul1 compared to the untreated sample, implying that $\mathrm{Csn} 5$ is active during oxidation (Figure 6B, lane 4). The insensitivity of Csn5 activity to $\mathrm{H}_{2} \mathrm{O}_{2}$ is not surprising since MPN+/JAMM metalloproteases exclude cysteine at the active site [69]; however, this is the first study to show constitutive CSN activity after $\mathrm{H}_{2} \mathrm{O}_{2}$ oxidation. Moreover, we evaluated if CSN subunit expression is altered in growth phases characterized by accumulated ROS (i.e., the diauxic shift). Our data revealed that at least one subunit, Csn10, expresses higher in the diauxic and post-diauxic phases (9-24 h) than in the logarithmic growth phase $(6 \mathrm{~h})$ (Figure 6C). Overall, the above indicates that the CSN is expressed and active in an oxidative environment.

The induction of CSN expression at the oxidative phase could suggest that this enzyme is required for oxidative stress tolerance. Indeed, treatment of $\Delta \operatorname{csn} 5$ cells with DCFDA revealed that Csn5-deficient cells produce high ROS (Figure 6D). The findings that $\Delta \operatorname{csn} 5$ mutant cells produce high ROS may be in conflict with the previous finding that yCul1 is fully neddylated in this mutant [46], since ROS inhibits the neddylation cascade [49]. Accordingly, there should have been a population of non-neddylated cullins as well. Despite this estimation, even a treatment of $\Delta c s n 5$ mutant cells with $\mathrm{H}_{2} \mathrm{O}_{2}$ revealed the total accumulation of neddylated yCul1, yCul3, and Rtt101, the three S. cerevisiae cullins (Figure 6E). The results were in line with the finding that treatment of wildtype cells with CSN5i-3 led to a high yCul1 neddylation status, even though the cells produced ROS (Figure 6F). These findings can be explained if single-enzyme removal of Rub1 is a more efficient process than the reverse process that requires a series of enzymes. 
A.

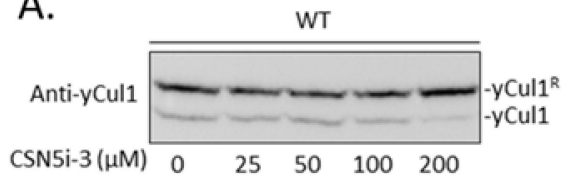

B.

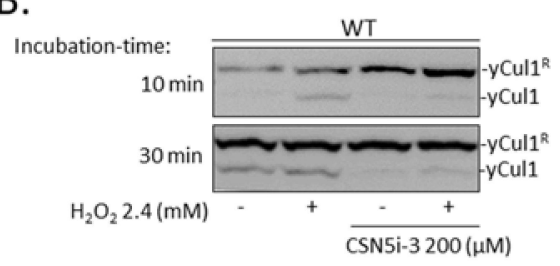

C.

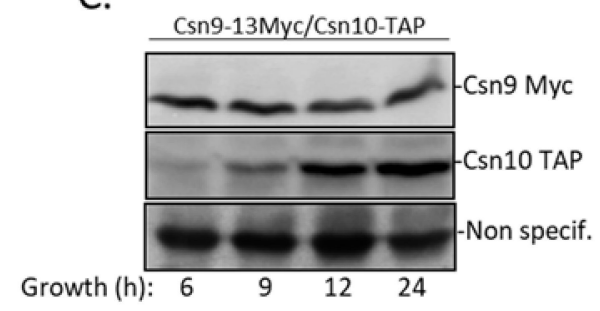

D.

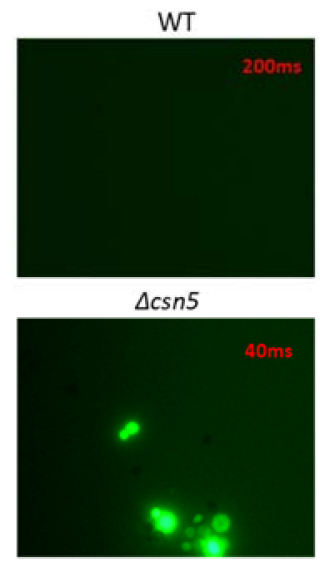

E.

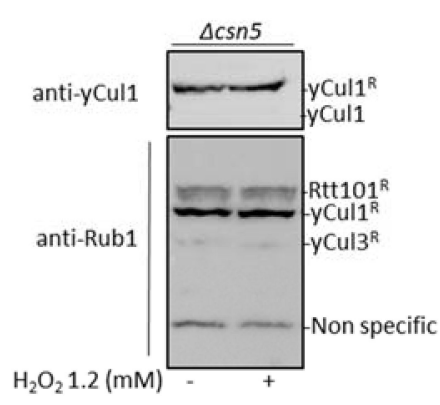

F.

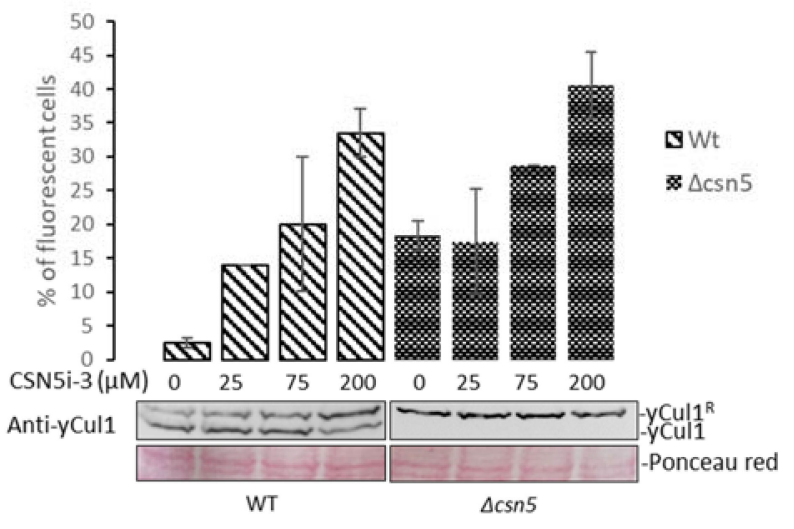

Figure 6. CSN activity in oxidized condition. (A) Logarithmic wildtype (WT) cells were treated with CSN5i-3 for $2 \mathrm{~h}$ as indicated and immunoblotted for yCul1. (B) Logarithmic wildtype cells were treated with $200 \mu \mathrm{M}$ of CSN5i-3 for $2 \mathrm{~h}$ before adding $2.4 \mathrm{mM} \mathrm{H}_{2} \mathrm{O}_{2}$ for 10 or $30 \mathrm{~min}$ before immunoblotted for yCul1. (C) The expression of CSN subunits was evaluated overtime in a wildtype strain in which Csn9 is C-terminally tagged by 13Myc and Csn10 is C-terminally TAP tagged. Myc antibodies and rabbit IgG were used for immunoblotting. (D) Wildtype and $\Delta \operatorname{csn} 5$ cells were treated with DCFDA and fluorescence was viewed by microscope. Notably, the mutant fluorescence was much higher than wildtype; thus, images were taken in a lower intensity $(40 \mathrm{~ms})$. (E) Logarithmic $\Delta c s n 5$ mutant cells were treated with $\mathrm{H}_{2} \mathrm{O}_{2}$ for at least $30 \mathrm{~min}$ and cullin neddylation status was assessed by immunoblotting with antibodies for yCul1 (top) or for Rub1 (bottom), recognizing the three yeast neddylated cullins (yCul1, Rtt101, and yCul3). (F) Endogenous ROS levels of wildtype and $\Delta c s n 5$ cells with and without the inhibitor $(0,25,75$, and $200 \mu \mathrm{M})$ were observed following DCFDA treatment. Two random fields were selected for each sample during quantification. The average intensity was calculated based on the number of fluorescent cells in the fields. Immunoblots are shown for yCul1 neddylation status; ponceau red is a loading marker.

Considering that CSN activity does not regulate the turnover of S. cerevisiae CRLs, the results could imply that the release of Rub1 from yCul1 is required to tackle cellular oxidative states through a CRL-free mechanism. Indeed, several studies suggested that NEDD8 and Rub1 orthologues are involved in the cellular response to oxidation [49,70,71]. To evaluate if the accumulation of ROS in $\Delta \operatorname{csn} 5$ is due to the lack of deneddylation, logarithmic wildtype cells were treated by CSN5i-3 $(0,25,75$, and $200 \mu \mathrm{M})$ for $2 \mathrm{~h}$ followed by DCFDA for one hour prior to harvest, and the percentage of fluorescent cells was calculated. Our data revealed that $25 \mu \mathrm{M}$ of CSN5i-3 induced ROS in wildtype cells (Figure 6E). This information is surprising because no effect on yCul1 neddylation was observed after treatment with $25 \mu \mathrm{M}$ CSN5i-3 (Figure 6A). Moreover, higher concentrations of CSN5i-3 led to higher ROS also in the $\Delta \operatorname{csn} 5$ mutant cells, leading to the suspicion that the inhibitor has other effects on cell physiology, in addition to CSN inhibition. These aspects should be studied in details. Notably, by using CSN5i-3, we did not observe in wildtype other phenotypes of $\Delta c s n 5$ such as defects in ergosterol biosynthesis or enlarged vacuoles [48] (Figure S6). Considering the generation time of S. cerevisiae ( $2 \mathrm{~h})$, we speculate that the lack of physiological phenotypes, such as alterations in lipids, was due to the short exposure of cells to the inhibitor $(2 \mathrm{~h})$. The short exposure might promote 
rapid metabolic changes in respiration or accumulation of ROS without inducing changes resulting from the synthesis or breakdown of macromolecules like lipids. These results should be further examined in the future, after prolonged treatment of cell with the drug. In conclusion, we were able to show through subunit interactions and models of homology that the CSN deneddylase center is conserved. This has been proven by the development of a general substrate (8His-yCul1-GFP-Rub1) and identification of a general inhibitor (CSN5i-3), suitable for CSN studies in diverged eukaryotes.

\section{Concluding Remarks}

In this study, the simplest eukaryotic model organism, S. cerevisiae, which harbors the most diverged CSN complex, was harnessed instrumentally for CSN studies. Endogenous neddylation enzymes within this organism have been used to engineer a purifiable version of SCF that is covalently attached to a fluorogenic Rub1 that successfully used as a general substrate for a CSN activity readout assay, measured by a fluorimeter. This universal, fast, and cheap assay had an advantage over other methods [72]. Future studies will include adjustment of the assay for detection of endogenous levels of CSN activity, which could further serve as an inexpensive universal method for evaluating enzyme activity even in non-model organisms in their natural habitats. Such research can be of great value, especially when considering the growing interest in environmental research, including the interplay between genome-based biology and environmental exposures, including climate change and outcomes such as global warming, drought, oxidation, salinity, pollution, or radiation.

Csn5-i3 was initially selected for inhibition of the human CSN. Considering the evolutionarily conserved MPN+/JAMM motif, it is not surprising that the inhibitor is also targeted by the yeast complex. Our results suggest that high doses of the inhibitor affect additional physiological pathways in yeast, which will need to be further deciphered. The data could only be obtained because of the non-essentiality of Csn5 in this organism. We expect these studies to be a cornerstone for selecting additional derivatives of CSN inhibitors [73], and to examine their possible side effects in the S. cerevisiae $\Delta c s n 5$ mutant, or in other fungal species that sustain non-essential CSNs.

Supplementary Materials: The following are available online at https: / www.mdpi.com/article/ 10.3390/biom11040497/s1, Figure S1: Structural comparison between Homo sapiens and Saccharomyces cerevisiae orthologues of CSN5; Figure S2: Evaluating interactions between CSN subunits; Figure S3: Superimposition of the S. cerevisiae CSN deNEDDylase core complex with the corresponding H. sapiens CSN; Figure S4: Neddylation status of the 8His-C548 truncation mutant; Figure S5: Cullin neddylation status in $\Delta$ pdr5 cells is not affected by $\mathrm{H} 2 \mathrm{O} 2$; Figure S6: Testing the phenotype of S. cerevisiae cells pre-treated with CSN5i-3; Table S1: Plasmids; Table S2: S. cerevisiae strains; Table S3: DNA primers; Table S4: complementary for Figure 1; Supplemental Alignment.

Author Contributions: D.H.-S., S.H. and N.C. performed all the experiments; superimposition, and modeling of structures, R.I.; validation, D.H.-S., N.C. and S.H.; formal analysis, E.P.; investigation, D.H.-S., S.H. and N.C.; resources, E.P.; data curation, R.I. and E.P.; writing-original draft preparation, N.C., D.H.-S., R.I. and E.P.; writing-review and editing, E.P.; supervision, E.P.; project administration, E.P.; funding acquisition, E.P. All authors have read and agreed to the published version of the manuscript.

Funding: This research was funded by the Israeli Science Foundation (ISF), grant number 162/17.

Institutional Review Board Statement: Not applicable.

Informed Consent Statement: Not applicable.

Data Availability Statement: Not applicable.

Acknowledgments: We thank Novartis Institute for Medical Research for supplying the CSN5/Jab1 inhibitor, CSN5i-3, under the terms of a Novartis Transfer Agreement for academic research purposes (inhibition of neddylation activity of the CSN complex of yeast and other species). We also thank 
Amnon Golan (the protein center, https:/ / proteasome.net/; accessed on 20 December 2019) for providing us the human CSN complex for our studies.

Conflicts of Interest: The authors declare no conflict of interest.

\section{References}

1. Balch, W.E.; Morimoto, R.I.; Dillin, A.; Kelly, J.W. Adapting proteostasis for disease intervention. Science 2008, 319, 916-919. [CrossRef]

2. Deshaies, R.J. Structural biology: Corralling a protein-degradation regulator. Nature 2014, 512, 145-146. [CrossRef]

3. Powers, E.T.; Morimoto, R.I.; Dillin, A.; Kelly, J.W.; Balch, W.E. Biological and chemical approaches to diseases of proteostasis deficiency. Annu. Rev. Biochem. 2009, 78, 959-991. [CrossRef]

4. Reinstein, E.; Ciechanover, A. Narrative review: Protein degradation and human diseases: The ubiquitin connection. Ann. Intern. Med. 2006, 145, 676-684. [CrossRef]

5. Nedelsky, N.B.; Todd, P.K.; Taylor, J.P. Autophagy and the ubiquitin-proteasome system: Collaborators in neuroprotection. Biochim. Biophys. Acta 2008, 1782, 691-699. [CrossRef]

6. Ciechanover, A. Intracellular protein degradation: From a vague idea through the lysosome and the ubiquitin-proteasome system and onto human diseases and drug targeting. Bioorg. Med. Chem. 2013, 21, 3400-3410. [CrossRef] [PubMed]

7. Mani, A.; Gelmann, E.P. The ubiquitin-proteasome pathway and its role in cancer. J. Clin. Oncol. 2005, 23, 4776-4789. [CrossRef] [PubMed]

8. Collins, G.A.; Goldberg, A.L. The Logic of the 26S Proteasome. Cell 2017, 169, 792-806. [CrossRef]

9. Cappadocia, L.; Lima, C.D. Ubiquitin-like Protein Conjugation: Structures, Chemistry, and Mechanism. Chem. Rev. 2017. [CrossRef]

10. Hu, H.Y. Protein Ubiquitination and Deubiquitination. Curr. Protein Pept. Sci. 2012, 13, 413. [CrossRef] [PubMed]

11. Tanaka, K.; Suzuki, T.; Chiba, T. The ligation systems for ubiquitin and ubiquitin-like proteins. Mol. Cells 1998, 8, 503-512.

12. Finley, D.; Ulrich, H.D.; Sommer, T.; Kaiser, P. The Ubiquitin-Proteasome System of Saccharomyces cerevisiae. Genetics 2012, 192, 319-360. [CrossRef] [PubMed]

13. Hanna, J.; Finley, D. A proteasome for all occasions. FEBS Lett. 2007, 581, 2854-2861. [CrossRef]

14. Pick, E.; Hofmann, K.; Glickman, M.H. PCI complexes: Beyond the proteasome, CSN, and eIF3 Troika. Mol. Cell 2009, 35, 260-264. [CrossRef] [PubMed]

15. Glickman, M.H.; Rubin, D.M.; Coux, O.; Wefes, I.; Pfeifer, G.; Cjeka, Z.; Baumeister, W.; Fried, V.A.; Finley, D. A subcomplex of the proteasome regulatory particle required for ubiquitin-conjugate degradation and related to the COP9-signalosome and eIF3. Cell 1998, 94, 615-623. [CrossRef]

16. Scheel, H.; Hofmann, K. Prediction of a common structural scaffold for proteasome lid, COP9-signalosome and eIF3 complexes. BMC Bioinform. 2005, 6, 71. [CrossRef]

17. Ambroggio, X.I.; Rees, D.C.; Deshaies, R.J. JAMM: A Metalloprotease-Like Zinc Site in the Proteasome and Signalosome. PLoS Biology 2004, 2, e2. [CrossRef]

18. Schmaler, T.; Dubiel, W. Control of Deneddylation by the COP9 Signalosome. Subcell. Biochem. 2010, 54, 57-68. [CrossRef]

19. Maytal-Kivity, V.; Reis, N.; Hofmann, K.; Glickman, M.H. MPN+, a putative catalytic motif found in a subset of MPN domain proteins from eukaryotes and prokaryotes, is critical for Rpn11 function. BMC Biochem. 2002, 3, 28. [CrossRef]

20. Verma, R.; Aravind, L.; Oania, R.; McDonald, W.H.; Yates, J.R., III; Koonin, E.V.; Deshaies, R.J. Role of Rpn11 Metalloprotease in Deubiquitination and Degradation by the 26S Proteasome. Science 2002, 298, 611-615. [CrossRef] [PubMed]

21. Cope, G.A.; Suh, G.S.; Aravind, L.; Schwarz, S.E.; Zipursky, S.L.; Koonin, E.V.; Deshaies, R.J. Role of Predicted Metalloprotease Motif of Jab1/Csn5 in Cleavage of NEDD8 from CUL1. Science 2002, 298, 608-611. [CrossRef]

22. Lyapina, S.; Cope, G.; Shevchenko, A.; Serino, G.; Tsuge, T.; Zhou, C.; Wolf, D.A.; Wei, N.; Shevchenko, A.; Deshaies, R.J. Promotion of NEDD-CUL1 conjugate cleavage by COP9 signalosome. Science 2001, 292, 1382-1385. [CrossRef] [PubMed]

23. Baek, K.; Krist, D.T.; Prabu, J.R.; Hill, S.; Klugel, M.; Neumaier, L.M.; von Gronau, S.; Kleiger, G.; Schulman, B.A. NEDD8 nucleates a multivalent cullin-RING-UBE2D ubiquitin ligation assembly. Nature 2020, 578, 461-466. [CrossRef] [PubMed]

24. Soucy, T.A.; Smith, P.G.; Milhollen, M.A.; Berger, A.J.; Gavin, J.M.; Adhikari, S.; Brownell, J.E.; Burke, K.E.; Cardin, D.P.; Critchley, S.; et al. An inhibitor of NEDD8-activating enzyme as a new approach to treat cancer. Nature 2009, 458, 732-736. [CrossRef] [PubMed]

25. Toth, J.I.; Yang, L.; Dahl, R.; Petroski, M.D. A gatekeeper residue for NEDD8-activating enzyme inhibition by MLN4924. Cell Rep. 2012, 1, 309-316. [CrossRef]

26. Schlierf, A.; Altmann, E.; Quancard, J.; Jefferson, A.B.; Assenberg, R.; Renatus, M.; Jones, M.; Hassiepen, U.; Schaefer, M.; Kiffe, M.; et al. Targeted inhibition of the COP9 signalosome for treatment of cancer. Nat. Commun. 2016, 7, 13166. [CrossRef]

27. Wei, N.; Chamovitz, D.A.; Deng, X.W. Arabidopsis COP9 is a component of a novel signaling complex mediating light control of plant development. Cell 1994, 78, 117-124. [CrossRef]

28. Chamovitz, D.A.; Wei, N.; Osterlund, M.T.; von Arnim, A.G.; Staub, J.M.; Matsui, M.; Deng, X.W. The COP9 complex, a novel multisubunit nuclear regulator involved in light control of a plant development switch. Cell 1996, 86, 115-121. [CrossRef]

29. Seeger, M.; Gordon, C.; Ferrell, K.; Dubiel, W. Characteristics of $26 \mathrm{~S}$ proteases from fission yeast mutants which arrest in mitosis. J. Mol. Biol. 1996, 263, 423-431. [CrossRef] 
30. Wei, N.; Serino, G.; Deng, X.W. The COP9 signalosome: More than a protease. Trends Biochem. Sci. 2008, 33, 592-600. [CrossRef]

31. Schwechheimer, C.; Isono, E. The COP9 signalosome and its role in plant development. Eur. J. Cell Biol. 2010, 89, 157-162. [CrossRef]

32. Oron, E.; Mannervik, M.; Rencus, S.; Harari-Steinberg, O.; Neuman-Silberberg, S.; Segal, D.; Chamovitz, D.A. COP9 signalosome subunits 4 and 5 regulate multiple pleiotropic pathways in Drosophila melanogaster. Development 2002, 129, 4399-4409.

33. Zhao, R.; Yeung, S.C.; Chen, J.; Iwakuma, T.; Su, C.H.; Chen, B.; Qu, C.; Zhang, F.; Chen, Y.T.; Lin, Y.L.; et al. Subunit 6 of the COP9 signalosome promotes tumorigenesis in mice through stabilization of MDM2 and is upregulated in human cancers. J. Clin. Investig. 2011, 121, 851-865. [CrossRef]

34. Braus, G.H.; Irniger, S.; Bayram, O. Fungal development and the COP9 signalosome. Curr. Opin. Microbiol. 2010, 13, 672-676. [CrossRef]

35. Pick, E. The necessity of NEDD8/Rub1 for vitality and its association with mitochondria-derived oxidative stress. Redox Biol. 2020, 37, 101765. [CrossRef] [PubMed]

36. Cavadini, S.; Fischer, E.S.; Bunker, R.D.; Potenza, A.; Lingaraju, G.M.; Goldie, K.N.; Mohamed, W.I.; Faty, M.; Petzold, G.; Beckwith, R.E.; et al. Cullin-RING ubiquitin E3 ligase regulation by the COP9 signalosome. Nature 2016, 531, 598-603. [CrossRef]

37. Lingaraju, G.M.; Bunker, R.D.; Cavadini, S.; Hess, D.; Hassiepen, U.; Renatus, M.; Fischer, E.S.; Thoma, N.H. Crystal structure of the human COP9 signalosome. Nature 2014, 512, 161-165. [CrossRef] [PubMed]

38. Mosadeghi, R.; Reichermeier, K.M.; Winkler, M.; Schreiber, A.; Reitsma, J.M.; Zhang, Y.; Stengel, F.; Cao, J.; Kim, M.; Sweredoski, M.J.; et al. Structural and kinetic analysis of the COP9-Signalosome activation and the cullin-RING ubiquitin ligase deneddylation cycle. Elife 2016, 5. [CrossRef] [PubMed]

39. Kato, J.Y.; Yoneda-Kato, N. Mammalian COP9 signalosome. Genes Cells 2009, 14, 1209-1225. [CrossRef]

40. Liu, C.; Guo, L.Q.; Menon, S.; Jin, D.; Pick, E.; Wang, X.; Deng, X.W.; Wei, N. COP9 signalosome subunit Csn8 is involved in maintaining proper duration of the G1 phase. J. Biol. Chem. 2013, 288, 20443-20452. [CrossRef]

41. Claret, F.X.; Hibi, M.; Dhut, S.; Toda, T.; Karin, M. A new group of conserved coactivators that increase the specificity of AP-1 transcription factors. Nature 1996, 383, 453-457. [CrossRef]

42. Yoshida, A.; Yoneda-Kato, N.; Kato, J.Y. CSN5 specifically interacts with CDK2 and controls senescence in a cytoplasmic cyclin E-mediated manner. Sci. Rep. 2013, 3, 1054. [CrossRef]

43. Tomoda, K.; Kato, J.Y.; Tatsumi, E.; Takahashi, T.; Matsuo, Y.; Yoneda-Kato, N. The Jab1/COP9 signalosome subcomplex is a downstream mediator of Bcr-Abl kinase activity and facilitates cell-cycle progression. Blood 2005, 105, 775-783. [CrossRef]

44. Pick, E.; Golan, A.; Zimbler, J.Z.; Guo, L.; Sharaby, Y.; Tsuge, T.; Hofmann, K.; Wei, N. The Minimal Deneddylase Core of the COP9 Signalosome Excludes the Csn6 MPN(-) Domain. PLoS ONE 2012, 7, e43980. [CrossRef] [PubMed]

45. Yu, Z.; Kleifeld, O.; Lande-Atir, A.; Bsoul, M.; Kleiman, M.; Krutauz, D.; Book, A.; Vierstra, R.D.; Hofmann, K.; Reis, N.; et al. Dual function of Rpn5 in two PCI complexes, the 26S proteasome and COP9 signalosome. Mol. Biol. Cell 2011, 22, 911-920. [CrossRef] [PubMed]

46. Maytal-Kivity, V.; Pick, E.; Piran, R.; Hofmann, K.; Glickman, M.H. The COP9 signalosome-like complex in S. cerevisiae and links to other PCI complexes. Int. J. Biochem. Cell Biol. 2003, 35, 706-715. [CrossRef]

47. Maytal-Kivity, V.; Piran, R.; Pick, E.; Hofmann, K.; Glickman, M.H. COP9 signalosome components play a role in the mating pheromone response of $S$. cerevisiae. EMBO Rep. 2002, 12, 1215-1221. [CrossRef] [PubMed]

48. Sinha, A.; Israeli, R.; Cirigliano, A.; Gihaz, S.; Trabelcy, B.; Braus, G.H.; Gerchman, Y.; Fishman, A.; Negri, R.; Rinaldi, T.; et al. The COP9 signalosome mediates the Spt23 regulated fatty acid desaturation and ergosterol biosynthesis. FASEB J. 2020. [CrossRef]

49. Bramasole, L.; Sinha, A.; Gurevich, S.; Radzinski, M.; Klein, Y.; Panat, N.; Gefen, E.; Rinaldi, T.; Jimenez-Morales, D.; Johnson, J.; et al. Proteasome lid bridges mitochondrial stress with Cdc53/Cullin1 NEDDylation status. Redox Biol. 2019, 20, 533-543. [CrossRef]

50. Liakopoulos, D.; Doenges, G.; Matuschewski, K.; Jentsch, S. A novel protein modification pathway related to the ubiquitin system. EMBO J. 1998, 17, 2208-2214. [CrossRef] [PubMed]

51. Liakopoulos, D.; Busgen, T.; Brychzy, A.; Jentsch, S.; Pause, A. Conjugation of the ubiquitin-like protein NEDD8 to cullin-2 is linked to von Hippel-Lindau tumor suppressor function. Proc. Natl. Acad. Sci. USA 1999, 96, 5510-5515. [CrossRef]

52. Eisele, M.R.; Reed, R.G.; Rudack, T.; Schweitzer, A.; Beck, F.; Nagy, I.; Pfeifer, G.; Plitzko, J.M.; Baumeister, W.; Tomko, R.J., Jr.; et al. Expanded Coverage of the 26S Proteasome Conformational Landscape Reveals Mechanisms of Peptidase Gating. Cell Rep. 2018, 24, 1301-1315.e1315. [CrossRef]

53. Wehmer, M.; Rudack, T.; Beck, F.; Aufderheide, A.; Pfeifer, G.; Plitzko, J.M.; Forster, F.; Schulten, K.; Baumeister, W.; Sakata, E. Structural insights into the functional cycle of the ATPase module of the 26S proteasome. Proc. Natl. Acad. Sci. USA 2017, 114, 1305-1310. [CrossRef]

54. Dessau, M.; Halimi, Y.; Erez, T.; Chomsky-Hecht, O.; Chamovitz, D.A.; Hirsch, J.A. The Arabidopsis COP9 signalosome subunit 7 is a model PCI domain protein with subdomains involved in COP9 signalosome assembly. Plant Cell 2008, 20, 2815-2834. [CrossRef] [PubMed]

55. Wee, S.; Hetfeld, B.; Dubiel, W.; Wolf, D.A. Conservation of the COP9/signalosome in budding yeast. BMC Genet. 2002, 3, 15. [CrossRef] 
56. Unverdorben, P.; Beck, F.; Śledź, P.; Schweitzer, A.; Pfeifer, G.; Plitzko, J.M.; Baumeister, W.; Förster, F. Deep classification of a large cryo-EM dataset defines the conformational landscape of the 26S proteasome. Proc. Natl. Acad. Sci. USA 2014, 111, 5544-5549. [CrossRef]

57. Faull, S.V.; Lau, A.M.C.; Martens, C.; Ahdash, Z.; Hansen, K.; Yebenes, H.; Schmidt, C.; Beuron, F.; Cronin, N.B.; Morris, E.P.; et al. Structural basis of Cullin 2 RING E3 ligase regulation by the COP9 signalosome. Nat. Commun. 2019, 10, 3814. [CrossRef]

58. Biasini, M.; Bienert, S.; Waterhouse, A.; Arnold, K.; Studer, G.; Schmidt, T.; Kiefer, F.; Gallo Cassarino, T.; Bertoni, M.; Bordoli, L.; et al. SWISS-MODEL: Modelling protein tertiary and quaternary structure using evolutionary information. Nucleic Acids Res. 2014, 42, W252-W258. [CrossRef]

59. Benkert, P.; Tosatto, S.C.; Schomburg, D. QMEAN: A comprehensive scoring function for model quality assessment. Proteins 2008, 71, 261-277. [CrossRef]

60. Kelley, L.A.; Mezulis, S.; Yates, C.M.; Wass, M.N.; Sternberg, M.J.E. The Phyre2 web portal for protein modeling, prediction and analysis. Nat. Protoc. 2015, 10, 845-858. [CrossRef]

61. Michnick, S.W.; Ear, P.H.; Landry, C.; Malleshaiah, M.K.; Messier, V. A toolkit of protein-fragment complementation assays for studying and dissecting large-scale and dynamic protein-protein interactions in living cells. Methods Enzymol. 2010, 470, 335-368. [CrossRef]

62. Sarikas, A.; Hartmann, T.; Pan, Z.Q. The cullin protein family. Genome Biol. 2011, 12, 220. [CrossRef] [PubMed]

63. Zaidi, I.W.; Rabut, G.; Poveda, A.; Scheel, H.; Malmstrom, J.; Ulrich, H.; Hofmann, K.; Pasero, P.; Peter, M.; Luke, B. Rtt101 and Mms1 in budding yeast form a CUL4(DDB1)-like ubiquitin ligase that promotes replication through damaged DNA. EMBO Rep. 2008, 9, 1034-1040. [CrossRef]

64. Patton, E.E.; Willems, A.R.; Sa, D.; Kuras, L.; Thomas, D.; Craig, K.L.; Tyers, M. Cdc53 is a scaffold protein for multiple Cdc34/Skp1/F-box proteincomplexes that regulate cell division and methionine biosynthesis in yeast. Genes Dev. 1998, 12, 692-705. [CrossRef]

65. Rabut, G.; Le Dez, G.; Verma, R.; Makhnevych, T.; Knebel, A.; Kurz, T.; Boone, C.; Deshaies, R.J.; Peter, M. The TFIIH subunit Tfb3 regulates cullin neddylation. Mol. Cell 2011, 43, 488-495. [CrossRef] [PubMed]

66. Scott, D.C.; Monda, J.K.; Grace, C.R.; Duda, D.M.; Kriwacki, R.W.; Kurz, T.; Schulman, B.A. A dual E3 mechanism for Rub1 ligation to Cdc53. Mol. Cell 2010, 39, 784-796. [CrossRef]

67. Hartwell, L.H.; Culotti, J.; Reid, B. Genetic control of the cell-division cycle in yeast. I. Detection of mutants. Proc. Natl. Acad. Sci. USA 1970, 66, 352-359. [CrossRef] [PubMed]

68. Kurz, T.; Ozlu, N.; Rudolf, F.; O’Rourke, S.M.; Luke, B.; Hofmann, K.; Hyman, A.A.; Bowerman, B.; Peter, M. The conserved protein DCN-1/Dcn1p is required for cullin neddylation in C. elegans and S. cerevisiae. Nature 2005, 435, 1257-1261. [CrossRef]

69. Cotto-Rios, X.M.; Bekes, M.; Chapman, J.; Ueberheide, B.; Huang, T.T. Deubiquitinases as a signaling target of oxidative stress. Cell Rep. 2012, 2, 1475-1484. [CrossRef]

70. Leidecker, O.; Matic, I.; Mahata, B.; Pion, E.; Xirodimas, D.P. The ubiquitin E1 enzyme Ube1 mediates NEDD8 activation under diverse stress conditions. Cell Cycle 2012, 11, 1142-1150. [CrossRef]

71. Keuss, M.J.; Hjerpe, R.; Hsia, O.; Gourlay, R.; Burchmore, R.; Trost, M.; Kurz, T. Unanchored tri-NEDD8 inhibits PARP-1 to protect from oxidative stress-induced cell death. EMBO J. 2019, 38, e100024. [CrossRef] [PubMed]

72. Golan, A.; Wei, N.; Pick, E. Immunodepletion and Immunopurification as Approaches for CSN Research. Methods Mol. Biol. 2016, 1449, 103-116. [CrossRef] [PubMed]

73. Cirigliano, A.; Stirpe, A.; Menta, S.; Mori, M.; Dell'Edera, D.; Pick, E.; Negri, R.; Botta, B.; Rinaldi, T. Yeast as a tool to select inhibitors of the cullin deneddylating enzyme Csn5. J. Enzyme Inhib. Med. Chem. 2016, 31, 1632-1637. [CrossRef] [PubMed] 